\title{
Uji Kesesuaian Kualitas Berkas Sinar-X Menggunakan Half Value Layer (HVL) Filter Aluminium Pada Pesawat Sinar-X Stationary di Akademi Teknik Radiodiagnostik dan Radioterapi Bali
}

\author{
X-ray Beam Quality Conformity Test Using Half Value Layer \\ (HVL) Aluminium Filter in Stationary X-ray Device at Academy \\ Teknik Radiodiagnostik and Radioterapi Bali
}

\author{
Ni Putu Pande Anita Yulianti ${ }^{1 *}$, Gusti Ngurah Sutapa ${ }^{1}$, Kadek Yuda Astina ${ }^{2}$ \\ ${ }^{1}$ Program Studi Fisika, Fakultas Matematika dan Ilmu Pengetahuan Alam, Universitas Udayana, \\ Kampus Bukit Jimbaran, Badung, Bali, Indonesia 80361 \\ ${ }^{2}$ Akademi Teknik Radiodiagnostik dan Radioterapi Bali, Jl. Tukad Batanghari VII No.21, Dauh Puri \\ Klod, Denpasar Selatan, Bali, Indonesia 80225 \\ Email: *pandeanita1999@gmail.com, sutapafis97@unud.ac.id, yudaastina@atro-bali.ac.id
}

\begin{abstract}
Abstrak - Telah dilakukan penelitian untuk mengetahui kualitas berkas sinar-X menggunakan half value layer (HVL) filter aluminium pada pesawat sinar-X stationary di Akademi Teknik Radiodiagnostik dan Radioterapi (ATRO) Bali. Penelitian ini bertujuan untuk mengetahui kualitas berkas sinar-X pada pesawat sinar-X stationary di ATRO Bali dengan melihat besarnya nilai HVL yang dihasilkan. Alat bantu yang digunakan berupa filter aluminium dengan tebal 0,5, 1,0, dan 2,0 mm, yang divariasi pada setiap besarnya arus yang digunakan, tegangan tabung konstan sebesar $80 \mathrm{kV}$, arus tabung 100, 125, 160, dan $200 \mathrm{~mA}$, waktu eksposi sebesar 0,1 detik dan multimeter sinar-X. Untuk mengetahui besar nilai HVL digunakan uji regresi linier menggunakan SPSS. Pada masing-masing arus tabung yang digunakan diperoleh nilai HVL rata-rata 2,77 mmAl. Hasil uji-t menunjukkan bahwa nilai HVL tersebut kurang sesuai dengan standar KMK nomor 1250 tahun 2009 yaitu dalam rentang $\geq 2,3$ mmAl sampai < 2,5 mmAl.
\end{abstract}

Kata kunci: Uji kesesuaian, sinar-X, HVL, kualitas berkas sinar-X, pesawat sinar-X stationary.

\begin{abstract}
A study was conducted to determine the quality of the X-ray beam using a half value layer (HVL) aluminum filter on a stationary X-ray device at the Akademi Teknik Radiodiagnostik dan Radiotherapi (ATRO) Bali. This study aims to determine the quality of the X-ray beam on a stationary $X$ ray device at ATRO Bali by looking at the magnitude of the HVL value produced. The tools used are aluminum filters with thicknes of 0.5, 1.0, and $2.0 \mathrm{~mm}$ which are varied for each current used, a constant tube voltage of $80 \mathrm{kV}$, tube currents of 100, 125, 160, and $200 \mathrm{~mA}$, exposure time of $0.1 \mathrm{~s}$ and an X-ray multimeter. The value of HVL was determined by linear regression test using SPSS. On each tube current used, the average HVL value was $2.77 \mathrm{mmAl}$. The $t$-test indicated that the HVL value is not in accordance with the KMK standard number 1250 in 2009 which is in the range of $\geq 2.3 \mathrm{mmAl}$ to $<2.5$ $m m A l$.
\end{abstract}

Key words: Conformity testing, X-ray, HVL, X-Ray beam quality, stationary X-ray device

\section{Pendahuluan}

Pemanfaatan sinar-X telah banyak digunakan pada bidang medis, khususnya untuk mendiagnosa kondisi klinis pasien. Salah satu peralatan yang digunakan sebagai penunjang diagnostik yaitu pesawat sinar-X stationary. Penggunaan pesawat sinar-X yang banyak digunakan untuk keperluan diagnosa mengharuskan untuk dilakukan uji kesesuaian pesawat sinar-X stationary tersebut. Uji kesesuaian pesawat sinar-X ini, juga harus dilakukan sebagai salah satu syarat perizinan pemanfaatan radiasi pengion ke Badan Pengawas Tenaga Nuklir (BAPETEN). Uji kesesuaian berfungsi untuk memastikan bahwa peralatan yang digunakan dalam prosedur radiologi diagnostik berfungsi dengan benar, sehingga pasien tidak mendapat paparan yang berlebih dan menerapkan program jaminan mutu untuk radiologi diagnostik. Salah satu kegunaan dari uji kesesuaian yaitu mengontrol nilai HVL yang dihasilkan pada 
pesawat sinar-X. Nilai HVL yang dihasilkan oleh pesawat sinar-X menunjukan kualitas berkas sinar-X pada pesawat tersebut [1].

Di Indonesia telah dikeluarkan KMK Republik Indonesia nomor 1250 tahun 2009 tentang Pedoman Kendali Mutu (quality control) peralatan radiodiagnostik. Dalam KMK nomor 1.250 diatur nilai minimal HVL dan harus dikontrol secara berkala setiap 1 tahun sekali. Pengontrolan nilai HVL adalah salah satu kegiatan dari quality control. Dalam KMK nomor 1250 dijelaskan bahwa standar nilai HVL pada tegangan $80 \mathrm{kVp}$ memiliki rentangan nilai $\mathrm{HVL} \geq 2,3 \mathrm{mmAl}$ sampai $<2,5 \mathrm{mmAl}$ [2]. Nilai $\mathrm{HVL}$ yang ditentukan dengan menggunakan aluminium sebagai filter juga dipersyaratkan dan ditentukan oleh Peraturan BAPETEN nomor 2 tahun 2018 [3].

Mutmainna pada tahun 2020 telah melakukan studi terkait nilai HVL untuk pesawat sinar-X mamografi digital di ruang Instalasi Radiologi RS Siloam Makasar. Dalam studi ini digunakan filter aluminium dan multimeter sinar-X Raysafe solo pada tegangan $23 \mathrm{kVp}$ sampai $33 \mathrm{kVp}$. Dari studi tersebut menyatakan bahwa nilai HVL yang dihasilkan memenuhi nilai batas toleransi yang distandarkan oleh BAPETEN nomor 2 tahun 2018 [4].

Berdasarkan uraian di atas, penulis melakukan studi lebih lanjut mengenai nilai HVL menggunakan pesawat sinar-X dengan tegangan $80 \mathrm{kVp}$ dan variasi arus tabung yang direkomendasikan KMK nomor 1250 sebesar 100, 125, 160 dan 200 mA. Studi ini bertujuan untuk menganalisis kualitas berkas sinar-X dengan membandingkan nilai HVL pesawat sinar-X di ATRO Bali dan nilai HVL standar dari KMK nomor 1.250 .

\section{Landasan Teori}

Pesawat sinar-X atau pesawat rontgen merupakan salah satu alat pencitraan medis yang memanfaatkan radiasi pengion berupa sinar-X. Sinar-X yang dipancarkan dari tabung inersia diarahkan ke bagian tubuh yang akan didiagnosis. Sinar-X akan menembus dan melewati bagian tubuh, kemudian ditangkap oleh film sehingga terbentuk citra bagian tubuh yang di eksposi [5]. Pesawat sinar-X terdiri dari control panel, transformator, generator dan tabung sinar-X. Dalam pengoperasian pesawat sinar-X, control panel digunakan sebagai pengatur parameter. Sistem sinar-X standar memiliki tiga prinsip pengendalian, yaitu tegangan tabung $(\mathrm{kV})$, arus tabung $(\mathrm{mA})$, dan waktu eksposi (s). Transformator adalah alat elektromagnetik yang dapat mengubah tegangan arus bolak-balik dan menaikkan atau menurunkan tegangan tabung. Generator berfungsi bukan untuk menyediakan atau membangkitkan energi, tetapi untuk mengubah energi listrik menjadi bentuk produksi sinar-X [6].

Tabung sinar-X merupakan salah satu komponen pesawat sinar-X, dimana tabung sinar-X merupakan ruang hampa udara yang terbuat dari kaca tahan panas, tempat dihasilkannya sinar-X. Untuk menghasilkan sinar-X diperlukan tabung sinar-X hampa udara, di mana dalam tabung tersebut terdapat elektron-elektron yang diarahkan pada target dengan kecepatan tinggi. Melalui proses di atas, muncul keadaan di mana sebagian besar energi elektron diubah menjadi panas (99\%) dan sebagian kecil (1\%) diubah menjadi sinar-X [7].

Terdapat beberapa jenis pesawat sinar- $\mathrm{X}$ seperti: pesawat sinar-X mobile merupakan pesawat sinar-X yang mudah dipindahkan dari satu ruangan ke ruang yang lain sedangkan pesawat sinar- $\mathrm{X}$ tetap (stationary) adalah pesawat yang terpasang tetap (stationary), yang digunakan untuk melakukan diagnosa medis dengan menggunakan sinar-X, baik untuk keperluan fluroskopi maupun radiografi [8].

Pada saat foton mengenai suatu bahan maka akan terjadi interaksi yang mengakibatkan penyerapan atau penghamburan foton. Proses penyerapan dan penghamburan akan berpengaruh pada attenuasi dari foton tersebut yang disebabkan oleh kerapatan, ketebalan dan nomor atom bahan yang dilalui. Apabila radiasi elektromagnetik masuk ke dalam bahan, maka sebagian dari radiasi tersebut akan terserap oleh bahan. Sebagai akibatnya, intensitas radiasi setelah memasuki bahan penyerap lebih kecil dibandingkan intensitas semula [1].

Filter merupakan suatu material yang didesain untuk menyerap berkas sinar-X. Filter berfungsi untuk menyaring berkas sinar-X yang keluar pada tabung sinar-X. Dalam hal ini, filter dibagi menjadi 2 yaitu inherent filter dan filter tambahan (filter eksternal). Inherent filter merupakan filter bawaan dari pesawat sinar-X yang sudah melekat pada pesawat tersebut, sedangkan filter tambahan merupakan filter yang diletakan di bawah bidang penyinaran [9].

Material filter yang umum digunakan dalam radiologi diagnostik yaitu aluminium ( $\mathrm{Al})$. Aluminium digunakan sebagai material filter dikarenakan mempunyai tingkat penyerapan yang sesuai untuk sinar-X. Standar internasional menetapkan aluminium jenis alloy 110 dengan kemurnian diatas $99 \%$ sebagai material filter yang baik untuk digunakan pada pesawat sinar-X [10]. 
HVL merupakan tebal bahan filter yang diperlukan untuk mengurangi intensitas sinar-X menjadi setengah intensitas awal [11]. Nilai HVL yang semakin besar disebabkan karena semakin banyak sinar-X yang menembus bahan. Metode pengukuran HVL menggunakan beberapa lempeng aluminium sebagai filter sehingga dihasilkan ketebalan yang variatif, kemudian ditembakkan sinar-X. Dari variasi ketebalan filter aluminium didapatkan suatu ketebalan yang menghasilkan setengah intensitas awal sinar-X. Dimana, intensitas awal adalah intensitas sinar-X tanpa melewati filter aluminium. Ketebalan filter aluminium yang menghasilkan setengah dari intensitas awal disebut sebagai HVL. Nilai HVL berfungsi sebagai indikator kualitas berkas sinar-X. Kualitas berkas sinar-X dipengaruhi oleh besarnya tegangan tabung yang digunakan, semakin besar tegangan tabung maka daya tembusnya semakin besar dan HVL yang dihasilkan semakin besar [1].

Nilai HVL yang dihasilkan harus memenuhi nilai minimum yang diatur dalam KMK nomor 1250 tahun 2009. Tabel 1 menunjukkan nilai minimum HVL untuk setiap penggunaan tegangan tinggi maksimum $(\mathrm{kVp})$ pada pesawat sinar-X [3].

Tabel 1. Persyaratan minimum HVL [3].

\begin{tabular}{lll}
\hline No & Measured $k V p$ & $\mathrm{HVL}(\mathrm{mmAl})$ \\
\hline 1 & 70 & 2,1 \\
2 & 80 & 2,3 \\
3 & 90 & 2,5 \\
4 & 100 & 2,7 \\
5 & 110 & 3,0 \\
6 & 120 & 3,2 \\
7 & 130 & 3,5 \\
8 & 140 & 3,8 \\
9 & 150 & 4,1 \\
\hline
\end{tabular}

\section{Metode Penelitian}

Penelitian ini dilakukan di ATRO Bali yang berlangsung dari Februari sampai April 2021. Alat-alat yang digunakan yaitu pesawat sinar-X, penggaris, filter eksternal bahan aluminium (kemurnian >99\%) dengan variasi ketebalan $0,5,1,0$, dan 2,0 mm, multimeter sinar-X dan detektor merek raysafe solo. Alat-alat tersebut ditunjukkan pada Gambar 1.

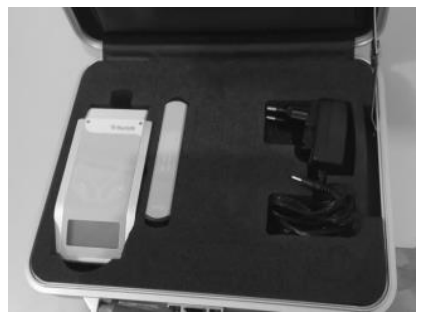

a)

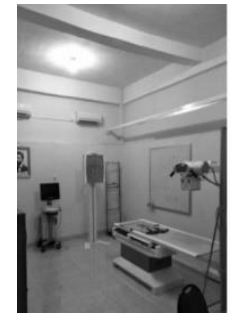

b)

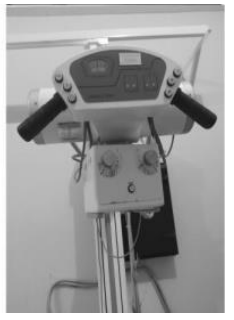

)

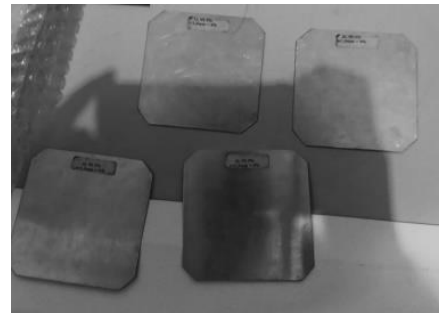

c)

Gambar 1. (a) Multimeter dan detektor sinar-X, (b) Pesawat sinar-X, dan (c) Filter aluminium [15].

Langkah pertama, dilakukan persiapan alat kemudian pesawat sinar-X dinyalakan dan dilakukan prosedur warm up dengan kolimator menghadap ke meja pemeriksaan. Jarak kolimator terhadap objek atau focus to film distance (FFD) diatur dengan jarak $30 \mathrm{~cm}$. Selanjutnya faktor eksposi diatur dengan tegangan tabung konstan sebesar $80 \mathrm{kVp}$, arus tabung sebesar $100 \mathrm{~mA}$ dan waktu penyinaran $0,1 \mathrm{~s}$. Bidang penyinaran diatur seluas filter yaitu $9 \mathrm{~cm} \times 9 \mathrm{~cm}$. Detektor diletakan tegak lurus dengan bidang penyinaran dan dihubungkan dengan multimeter sinar-X. Ekspos dilakukan pada detektor sinar-X tanpa menggunakan filter aluminium. Dosis yang terukur pada multimeter sinar-X dicatat. Filter aluminium dengan ketebalan $0,5 \mathrm{~mm}$ dilekatkan pada bidang penyinaran dan dilakukan pengeksposan. Dosis yang terukur pada multimeter sinar-X dicatat. Pengukuran tersebut dilakukan kembali dengan variasi ketebalan filter yang bertambah $0,5 \mathrm{~mm}$ hingga $5 \mathrm{~mm}$. Langkah diatas dilakukan kembali dengan variasi arus sebagai berikut, 125, 160 dan $200 \mathrm{~mA}$.

Adapun analisis data pada penelitian ini yaitu, data dosis dikelompokkan berdasarkan besarnya arus yang digunakan dan dirata-ratakan. Selanjutnya dilakukan perhitungan HVL dengan uji regresi linier pada program SPSS versi 25. Nilai HVL yang didapatkan melalui hasil perhitungan akan dibandingkan 
dengan KMK nomor 1.250 tahun 2009 dengan menggunakan uji-t satu arah pada program spss versi 25. Hipotesis statistik yang diajukan yaitu, $\mathrm{H}_{0}=$ tidak terdapat perbedaan antara nilai HVL hasil perhitungan dengan nilai $\mathrm{HVL}$ yang telah ditetapkan. $\mathrm{H}_{1}=$ terdapat perbedaan antara nilai $\mathrm{HVL}$ hasil perhitungan dengan nilai HVL yang telah ditetapkan. Nilai $\mathrm{p}$ value dicari menggunakan aplikasi SPSS. Apabila nilai $\mathrm{p}$ value $\geq 0,05$ maka hipotesis $\mathrm{H}_{0}$ diterima dan $\mathrm{H}_{1}$ ditolak dan sebaliknya.

\section{Hasil Dan Pembahasan}

Pada penelitian ini terukur besar dosis pada masing-masing tebal filter dan arus yang digunakan. Nilai dosis yang diperoleh kemudian dirata-ratakan seperti tampak pada Tabel 2.

Tabel 2. Dosis rata-rata pada masing-masing tebal filter dan arus.

\begin{tabular}{ccccc}
\hline $\begin{array}{c}\text { Tebal filter } \\
(\mathrm{mm})\end{array}$ & \multicolumn{4}{c}{ Dosis Rata-rata $(\mathrm{mGy})$} \\
\cline { 2 - 5 } & $100 \mathrm{~mA}$ & $125 \mathrm{~mA}$ & $160 \mathrm{~mA}$ & $200 \mathrm{~mA}$ \\
\hline 0 & 14,119 & 17,540 & 20,967 & 26,191 \\
0,5 & 11,440 & 14,709 & 16,870 & 19,462 \\
1,0 & 9,894 & 12,678 & 14,268 & 18,658 \\
1,5 & 8,633 & 11,072 & 12,916 & 16,436 \\
2,0 & 7,759 & 9,710 & 10,901 & 14,413 \\
2,5 & 6,936 & 8,673 & 10,111 & 12,994 \\
3,0 & 6,292 & 7,502 & 8,936 & 11,840 \\
3,5 & 5,634 & 7,064 & 8,565 & 11,486 \\
4,0 & 5,235 & 6,275 & 7,401 & 9,796 \\
4,5 & 4,713 & 5,878 & 7,026 & 8,990 \\
5,0 & 4,331 & 5,412 & 6,447 & 8,533 \\
\hline
\end{tabular}

Dari data pada Tabel 2 dilakukan uji regresi linier menggunakan program SPSS dimana tebal filter sebagai variabel independen dan dosis rata-rata sebagai variabel dependen. Uji ini menghasilkan persamaan regresi, yang digunakan untuk menghitung nilai HVL. Nilai HVL dihitung dengan mengganti variabel y pada persamaan regresi dengan nilai setengah dari dosis awal, HVL didapat melalui hasil variabel $x$. Berikut merupakan persamaan regresi dan hasil perhitungan nilai HVL menggunakan persamaan regresi tersebut, seperti tampak pada Tabel 3.

Tabel 3. Hasil perhitungan nilai HVL.

\begin{tabular}{llll}
\hline No & Arus $(\mathrm{mA})$ & Persamaan Regresi & HVL $(\mathrm{mmAl})$ \\
\hline 1 & 100 & $\mathrm{y}=-1,506 \mathrm{x}+11,229$ & 2,77 \\
2 & 125 & $\mathrm{y}=-1,992 \mathrm{x}+14,376$ & 2,81 \\
3 & 160 & $\mathrm{y}=-1,958 \mathrm{x}+15,519$ & 2,68 \\
4 & 200 & $\mathrm{y}=-2,535 \mathrm{x}+20,233$ & 2,82 \\
\hline
\end{tabular}

Berdasarkan Tabel 3 didapatkan persamaan regresi pada arus $100 \mathrm{~mA}$ yaitu y $=-1,506 \mathrm{x}+11,229$ dengan mensubsitusi nilai $y=7,0595$ menghasilkan nilai $x=2,77$. Nilai $x$ ini merupakan nilai HVL hasil perhitungan, sehingga nilai HVL pada arus $100 \mathrm{~mA}$ didapat sebesar 2,77 mmAl. Dengan menggunakan cara yang sama dapat dihitung nilai HVL pada arus 125, 160 dan $200 \mathrm{~mA}$ secara berturut-turut sebesar 2,81, 2,68, 2,82 mmAl. Dapat dilihat bahwa terjadi fluktuasi pada nilai HVL yang dihasilkan terhadap peningkatan arus tabung yang diberikan. Dalam teori HVL berfokus pada kualitas sinar-X yang digunakan. Kualitas sinar-X dapat diukur dari daya tembus sinar-X terhadap bahan yang dilalui. Kualitas sinar-X dipengaruhi oleh besar tegangan tabung yang digunakan dan arus tabung memberikan pengaruh yang tidak signifikan [1]. Nilai HVL hasil perhitungan ini dibandingkan dengan nilai HVL standar KMK nomor 1250 Tahun 2009 menggunakan uji-t satu arah.

Berdasarkan analisis data nilai HVL rata-rata hasil perhitungan yakni 2,77 $\mathrm{mmAl}$ dengan nilai $\mathrm{HVL}$ standar KMK nomor 1250 tahun 2009 dalam rentang $\geq 2,3 \mathrm{mmAl}$ sampai $<2,5 \mathrm{mmAl}$ menggunakan uji-t satu arah menghasilkan nilai $\mathrm{p}$ value $\leq 0,05$ yakni 0,001 . Oleh karena itu, $\mathrm{H}_{0}$ ditolak dan $\mathrm{H}_{1}$ diterima yakni nilai HVL hasil perhitungan lebih besar dari pada nilai HVL yang telah ditetapkan KMK nomor 1250. Dari analisa tersebut, dapat dikatakan bahwa nilai HVL yang dihasilkan pesawat sinar-X stationary di ATRO Bali memiliki kualitas berkas sinar-X yang kurang sesuai, dikarenakan nilai HVL yang dihasilkan melebihi standar yang telah ditetapkan KMK nomor 1250. Kondisi ini dapat disebabkan oleh beberapa faktor salah satunya posisi inherent filter yang kurang tepat. Inherent filter tidak dalam posisi 
tegak lurus dengan kolimator sehingga menyebabkan kualitas berkas sinar-X yang dihasilkan kurang optimal dan menyebabkan radiasi sekunder tidak tersaring dengan baik. Peningkatan radiasi sekunder dapat meningkatkan dosis radiasi yang diterima oleh objek atau pasien yang diperiksa serta mengurangi kualitas citra yang dihasilkan oleh pesawat sinar-X tersebut. Maka dari itu perlu dilakukan pengecekan kembali serta perbaikan pada pesawat sinar-X stationary (merek MIS Toshiba) di ATRO Bali untuk meningkatkan kualitas berkas sinar-X. Hal ini sejalan dengan program quality control dimana, setiap alat radiodiagnostik yang digunakan harus aman dan memenuhi proteksi radiasi.

\section{Kesimpulan}

Berdasarkan hasil penelitian ini, maka dapat disimpulkan sebagai berikut. Besar nilai HVL yang dihasilkan pesawat sinar-X stationary di ATRO Bali pada arus 100, 125, 160 dan $200 \mathrm{~mA}$ berturut-turut 2,77, 2,81, 2,68 dan 2,82 mmAl dengan rata-rata 2,77 mmAl. Hasil uji-t menunjukkan bahwa nilai HVL tersebut kurang sesuai dengan standar KMK nomor 1250 tahun 2009 yaitu dalam rentang $\geq 2,3 \mathrm{mmAl}$ sampai $<2,5 \mathrm{mmAl}$.

\section{Ucapan Terima Kasih}

Penulis menyampaikan terimakasih kepada seluruh staff di ATRO Bali yang telah memberikan izin dan bantuan berupa fasilitas dalam penelitian ini, serta staf dosen Program Studi Fisika, FMIPA, UNUD yang telah memberikan saran serta masukan terkait penelitian ini.

\section{Pustaka}

[1] D. H. Yunitasari, E. Setiawati, dan C. Anam, Evaluasi Metode Penentuan Half Value Layer (HVL) Menggunakan Multi Purpose Detector (MPD) Barracuda Pada Pesawat Sinar-X Mobile, Jurnal Fisika, vol. 3, no. 2, 2014, pp. 113-118.

[2] Keputusan Menteri Kesehatan, Pedoman Kendali Mutu (Quality Control) Peralatan Radiodiagnostik, Menteri Kesehatan Republik Indonesia, 2009, pp. 19-21.

[3] Badan Pengawas Tenaga Nuklir, Uji Kesesuaian Pesawat Sinar-X Radiologi Diagnostik dan Internasional, Badan Pengawasan Tenaga Nuklir Republik Indonesia, 2018, pp. 62.

[4] M. Akhadi, Dasar-Dasar Proteksi Radiasi, Jakarta, 2000.

[5] K. Miniati, G. N. Sutapa, dan B. Sudarsana, Uji Kelayakan Pesawat Sinar-X Terhadap Proyeksi Pa (Postero-Anterior) dan Lat (Lateral) Pada Teknik Pemeriksaan Foto Thorax, Jurnal Fisika, vol. 18, no. 1, 2017, pp. 27-31.

[6] L. G. P. Satwika, N. N. Ratini, dan M. Iffah, 2021, Pengaruh Variasi Tegangan Tabung Sinar-X Terhadap Signal to Noise Ratio (SNR) Dengan Penerapan Anode Heel Effect Menggunakan Stepwedge, Jurnal Fisika, vol. 22, no. 1, 2021, pp. 20-28.

[7] F. Suyatno, L. Yuniarsari, dan B. Syawaludin, Rancangan Sistem Instrumentasi Pembangkit SinarX Pada Pesawat Rontgen, Jurnal Batan, vol. 5, no. 2, 2009, pp. 151-165.

[8] N. Mukminah, R. Iswadi, dan Ihsan, Analisis Linearitas Keluaran Radiasi Pada X-Ray Mobile Dengan Menggunakan Piranha, Skripsi, Program Studi Fisika, Fakultas Sains dan Teknologi Universitas Islam Negeri Alauddin Makasar, 2014.

[9] S. Litasova, E. Hidayanto, dan M. Azam, Pengaruh Ketebalan Dan Kombinasi Jenis Filter Terhadap Nilai Entrance Skin Exposure (ESE) Menggunakan Faktor Eksposi Pemeriksaan Kepala, Jurnal Fisika Undip, vol. 7, no. 2, 2018, pp. 67-75.

[10] H. Dabukke, Pengujian Iluminasi, Kolimasi, Ketegaklurusan dan Kualitas Berkas Pesawat Sinar-X Radiografi Umum Dengan Radiografi Mobile, Tugas Akhir, Program Studi Fisika, Fakultas Matematika dan Ilmu Pengetahuan Alam Universitas Sumatera Utara, 2018.

[11] A. Mutmainna, D. S. Astuty, S. Dewang, dan Mulyadin, Uji Kesesuaian Standar Nilai HVL Filter Aluminium Pada Pesawat Sinar-X Mammografi Studi Kasus Di Ruang Instalasi Radiologi RS. Siloam Makasar, Jurnal Fisika, vol. 23, no. 1, 2020, pp. 17-25.

[12] D. K. Lestari, Studi Penentuan Kualitas Berkas Radiasi Pesawat Sinar-X Mammografi Di RSUD Kota Makasar, Skripsi, Jurusan Fisika, Fakultas Sains dan Teknologi Universitas Islam Negeri Alauddin Makasar, 2017. 